\title{
Editorial
}

\section{The brave new world of marketing - Only for the brave?}

Journal of Direct, Data and Digital Marketing Practice (2015) 16, 153. doi:10.1057/dddmp.2015.8

The goal of the IDM Journal is to track the changing nature of direct and digital marketing, identifying new techniques and emerging channels and, where possible, publishing success stories about them. At the same time, the Journal also tracks sustainable models, the survival of ways of working from one marketing era into another or the transferability of approaches between disciplines. It's all there in the name, after all.

As has already been discussed in these pages, what goes into the marketing mix is now more complex than ever. As a result, few marketers are able to develop domain specialisms in more than one or two areas. This is potentially a recipe for silos in which marketers communicate with prospects and customers through the channel they understand best, without considering either the alternatives or the over-arching experience.

All of this is happening at a time when brands are more visible to the marketplace than ever and customers have a higher expectation than before that the experience will be consistent and connected. Which brings to the forefront the middle ' $\mathrm{D}$ ' in the Journal's title - data. If you struggle to find people with the skills required to deliver effective search, engaging mobile apps or impactful websites, it is that much harder to find specialists who understand data, how it can be captured and managed, and what the compliance issues mean. Read the review of a discussion at the IDM Data Council on pages 238-240 and you will discover that even experts in this space struggle to understand what they can and cannot do and what their customers really expect from them.

Fail to connect the data back end with the digital delivery front end, however, and the entire marketing project falls apart. More than ever, this need to demonstrate to each individual that they are recognized, understood and engaged with is becoming visible in the mobile channel. Merlin Stone's piece on the evolution of the mobile industry (pp. 157-165) makes it clear how rapidly this sector has evolved.

This change is not just a challenge to marketing, it is a real opportunity. Paul Berney (pp. 166-168) argues that retail loyalty schemes - which a decade ago were the cutting edge of marketing and staple content of the IDM Journal - need to port into the mobile world to deliver fresh, new benefits to both shoppers and retailers. Consumers are turning to their mobiles to find discounts and offers even while they are in-store (see Ali Cort's article on pages 169-171), while the use of quick response or QR codes by marketers is making that shopping experience richer and more engaging (pp. 209-224). In some respects, it is a battle of wills between the consumer and the marketer.

That's why this is now a profession only for the brave. Get any one of the elements wrong - data, channel, proposition, journey - and you miss the chance to win a customer. The upside is that the whole process is more visible, manageable and direct than ever.

David Reed FIDM 